\title{
Role of Natural Antioxidants in the Modulation of Plasma Amino Acid Pattern in Rats Exposed to Hemic Hypoxia
}

\author{
Nouf Mohamed Al-Rasheed ${ }^{1}$, Laila Mohamed Fadda ${ }^{1}$, Nawal Mohamed Al-Rasheed ${ }^{1}$, Hala \\ Attia $^{1,2}$, Hanaa Mahmoud Ali ${ }^{3,4^{*}}$ and Hanaa El-Agami ${ }^{1}$ \\ ${ }^{1}$ Pharmacology Department; Faculty of Pharmacy; King Saud University; Riyadh - KSA. ${ }^{2}$ Department of \\ Biochemistry; Faculty of Pharmacy; Mansoura University; Mansoura - Egypt. ${ }^{3}$ Depatment of Genetics and \\ Cytology; National Research Center; Egypt. ${ }^{4}$ Preparatory Year Deanship; King Saud University; Riyadh - KSA
}

\begin{abstract}
The aim of this work was to investigate whether the free radical scavengers, L-arginine (L-arg) and/or carnosine, either alone, or in combination would modulate tissue injury induced by hypoxia by measuring Fischer's ratio [concentrations of branched chain amino acids (BCAAs)/aromatic amino acids]. Decreased Fischer's ratios and increased malondialdehyde (MDA) led to pathogeneses of many diseases. Rats were injected with sodium nitrite (60 $\mathrm{mg} / \mathrm{kg})$ to establish hypoxia. They were treated with L-arg, (200 mg/ kg) and/or carnosine (200 $\mathrm{mg} / \mathrm{kg})$ and their combination 24 and $1 \mathrm{~h}$ prior to sodium nitrite intoxication. The results revealed that hypoxia significantly decreased hemoglobin, arginine, citrulline and proline and increased SLDH, MDA, ammonia, urea, BCAAs (valine, leucine and isoleucine) and aromatic amino acids (phenylalanine and tyrosine). The Fischer's ratio was decreased compared with the control; the administration of the aforementioned antioxidants ameliorated most of the previously altered parameters. It was concluded that Fischer's ratio was a valuable tool for understanding the pathology of hemic hypoxia, evaluating the degree of the modulatory effect of various natural antioxidants and the synergy between L-arg and carnosine in ameliorating the effect of sodium nitrite on amino acids pattern. Thus, it could be recommended to administer the combination of L-arg and carnosine in the areas of high altitudes to combat the hazard effect of hypoxia on hemoglobin concentration and MDA level.
\end{abstract}

Key words: Natural antioxidants, Amino acids, Carnosine, L-arginine, Fisher's ratio, Urea

\section{INTRODUCTION}

Ischemia may lead to cerebral infarction, which is considered as one of the cerebral hypoxia- the major cause of death all over the world (Mohr et al. 1978). Exposure of human and laboratory animals to hypoxia results in metabolic failure (Elwyn 1970; Ferber et al. 1981; Muratsubaki et al. 2003), such as depletion of adenosine triphosphate (ATP) stores, enhanced anaerobic glycolysis, activation of calciumstimulated enzymes, mitochondrial dysfunction, and induced formation of reactive oxygen species (ROS) that produces tissue damage (Amerisco and Sahai 1997; Smis and Anderson 2002; Endres et al. 2004).

The toxicity of nitrite arises from the formation of $\mathrm{N}$-nitroso compounds. The acute toxic effect of nitrite moiety occurs through its ability to oxidize the oxyhemoglobin to methemoglobin, a substance that interferes with the ability of blood cells to carry oxygen in the body (Ger et al. 1996). Elevated levels of methemoglobin (more than 10\% of the total hemoglobin) causes cyanosis, or blue skin and brown blood. The affected person goes

*Author for correspondence: hsameh2312003@yahoo.com 
into anoxia, coma and may die (Linberg et al. 1998).

Nitric oxide (NO) produced by the endothelial isoform of nitric oxide synthase (NOS) is beneficial (Huang et al. 1996). Endothelial-derived NO may suppress neuronal damage through its powerful vasodilation effects on vascular beds (Zhang and Iadecola 1994). NO in the brain may have neuroprotective role via scavenging of ROS (Wink et al. 1995; Pluta et al. 2001) and by its anti-inflammatory effect (Bath et al. 1991). Antioxidants, prevent oxidative stress induced by the ROS and different oxidatives (Halliwell 1992; Palozza et al. 1997). Thus, antioxidants and/or free radical scavengers capable of easily crossing the brain barrier are candidates that provide protection in experimental hypoxia models (Hall et al. 1996). Therefore, administration of L-arginine (L-arg), which is a precursor for the synthesis of NO has been considered to be beneficial in the treatment of acute hypoxia (Cernadas et al. 1992; Hishikawa et al. 1992; Mehata et al. 1996; Salter et al. 1996; Schutz et al. 1997). L-arginine is a conditionally nonessential amino acid that has numerous functions in the body. L-arginine plays an important role in cell division, and immune function (Andrew and Mayer 1999; Witte and Barbul 2003; Wu et al. 2004; Stechmiller et al. 2005), reduces healing time of injuries, quickens repair time of damaged tissue (Senberg et al. 2005) and helps in decreasing blood pressure (Gokce 2004). Carnosine (beta-alanyl-L-histidine) is a dipeptide of the amino acids, beta-alanine and histidine. It is highly concentrated in muscle and brain tissues, It can chelate divalent metal ions, scavenges (ROS) as well as unsaturated aldehydes formed from the peroxidation of cell membrane fatty acids during oxidative stress (Ali 2012). It has been reported that carnosine inhibits mRNA expression of apoptosis-inducing factor (AIF) and caspase-3, increases superoxide dismutase (SOD) activity and decreases malondialdehyde (MDA) level when given to mice (Flock et al. 1951). The determination of plasma free amino acid levels is important when studying protein and amino acid metabolism. The branched chain amino acids (BCAAs), which include leucine, isoleucine, and valine, are readily metabolized in the muscle (Elwyn 1970), while aromatic amino acids (AAAs), which include phenylalanine and tyrosine are degraded in the liver. The plasma level of this latter group can be an indicator of tissue damage (Gonchar et al. 2006).
The objective of this study was to assess whether using L-arginine and/or carnosine, the free radical scavengers would ameliorate metabolic failure resulting from the experimental model of hemic hypoxia (sodium nitrite-induced hypoxia) in the rats, and if the combination regime give the most promising effect or the individual antioxidants.

\section{MATERIAL AND METHODS}

\section{Drugs and Chemicals}

L-Arginine, carnosine, and sodium nitrite as well as all other chemicals used in this study were analytically pure product of Sigma-Aldrich Chemical Co., St. Louis, MO, USA.

\section{Experimental Animals}

Male Wistar albino rats, weighing 180-200 g, were obtained from the Experimental Animal Care Center, College of Pharmacy, King Saud University, Riyadh, Saudi Arabia. The animals were housed in stainless steel cages (5 animals/cage), and acclimated with free access to tap water and standard pellet diet in at $22-24^{\circ} \mathrm{C}$ and $50 \%$ humidity on a 12 -h light/12-h dark cycle for one week before the experiment. All the animals were fasted for $3 \mathrm{~h}$ prior to drugs administration. The protocol of this study was approved by the Research Ethics Committee of College of Pharmacy, King Saud University, Riyadh, Kingdom of Saudi Arabia (KSA).

Rats were divided into five groups, ten rats each. (Group 1): normal animals treated with saline; (Group 2): Hypoxic group, rats were injected subcutaneously with sodium nitrite at $60 \mathrm{mg} / \mathrm{kg}$ (Gonchar et al. 2006); (Group 3): rats were treated with $200 \mathrm{mg} / \mathrm{kg}$ of L-arg (El-Missiry et al. 2004) $24 \mathrm{~h}$ then $1 \mathrm{~h}$ prior to sodium nitrite administration; (Group 4): animals were injected with carnosine $(200 \mathrm{mg} / \mathrm{kg}$, i.p) (Zhang et al. 2011) $24 \mathrm{~h}$ then $1 \mathrm{~h}$ prior to sodium nitrite administration. (Group 5): rats were treated with the same doses of L-arginine \& carnosine group: prior to sodium nitrite as the same protocol previously mentioned.

After $1 \mathrm{~h}$ of sodium nitrite injection, rats were sacrificed by cervical decapitation, blood was collected, and plasma and serum were separated and stored at $-80^{\circ} \mathrm{C}$ for the various biochemical evaluations. 
Biochemical Analysis

\section{Determination of Blood Hemoglobin}

Hemoglobin was assayed in the whole blood by its oxidation to methemoglobin with alkaline ferricyanide reagent (Drabkin's reagent), giving intensely colored cynmethemoglobin, which was measured at $540 \mathrm{~nm}$. The results are expressed as g/dl (Drabkin and Austin 1935).

\section{Determination Serum Biochemical Parameters Determination of LDH activity}

The activity of LDH was measured using the kits obtained from Bio-Mèrieux-RCS (Lyon, France).

\section{Determination of Malondialdehyde (MDA) level:}

MDA, as an index of lipid peroxidation, was measured according to the method of Ohkawa et al. (1979) using the kit provided by Randox Company. The pink color developed due to the reaction of malondialdehyde with thiobarbituric acid (TBA) in acid medium was measured spectrophotometrically at $520 \mathrm{~nm}$ and $535 \mathrm{~nm}$, using 1, 1, 3, 3- tetramethoxy propane as standard free malonyldialdehyde (MDA) standard curve, and extraction of the chromogen with n-butanol to increase the assay specificity.

\section{Determination of amino acid and enzyme concentrations}

Plasma amino acid concentrations were assayed using the High Performance Liquid Chromatography (HPLC) method of SRL Co., Inc. (Hachioji, Tokyo, Japan) (Kedenburg 1971).

\section{Calculation of Fischer's Ratio}

Fischer's ratio was calculated as the sum of the plasma valine, leucine and isoleucine (BCAAs) levels divided by the sum of the phenylalanine and tyrosine (AAAs) levels (Fischer et al. 1976).

\section{Statistical Analysis}

Data are expressed as mean \pm SEM. Differences between the groups were analyzed using one way analysis of variance (ANOVA), followed by Tukey Krammer posthoc multiple test. The level of significance was set at $\mathrm{p}<0.05, \mathrm{p}<0.01$ and $\mathrm{p}$ $<0.001$. Statistical analysis was performed using the Graph pad Instat 3 software Inc, San Diego, CA, USA. The limit of significance for Figures 1, 2 and 3 was $\mathrm{P}<0.05$; a: Significantly different from control group. b: Significantly different from sodium nitrite-treated group.

\section{RESULTS}

Effects of pretreatment with L-arginine and/or carnosine and their combination on blood Hemoglobin concentration as well as $\mathrm{LDH}$ and lipid peroxides serum levels

The present data revealed that hypoxia produced by sodium nitrite significantly decreased blood hemoglobin concentration and significantly increased serum activity of injury marker enzyme LDH as well as MDA levels compared with the normal control rats at $\mathrm{P}<0.05$.

Pretreatment of the hypoxic rats with L-arginine, or carnosine alone, or in combination significantly restored hemoglobin, LDH and MDA levels. The combination protocol exhibited best results in these concerns (Figs. 1, 2 and 3).

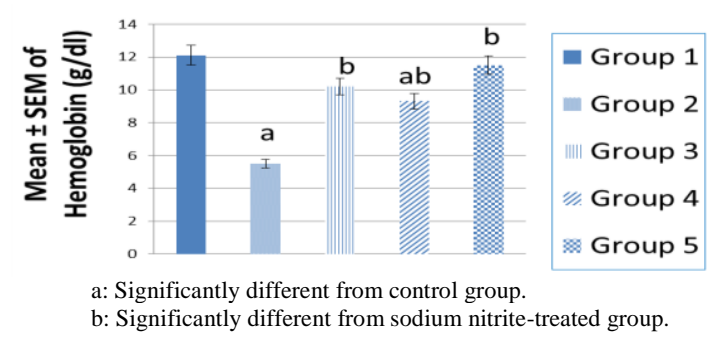

Figure 1 - Hemoglobin level in the blood of control, hypoxic and pretreated hypoxic rats with Larginine, or carnosine and L-arginine with carnosine.

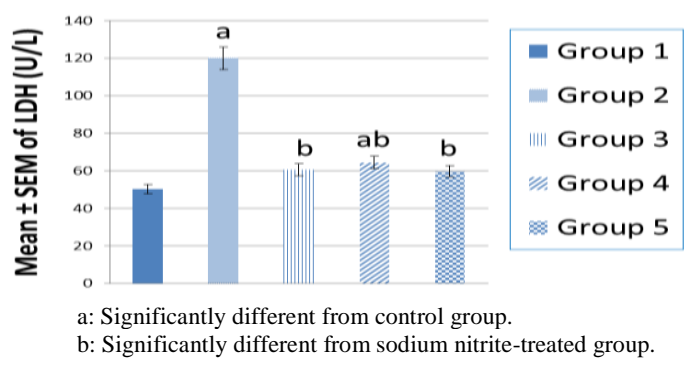

Figure 2 - Serum LDH level of control, hypoxic and pretreated hypoxic rats with L-arginine, or carnosine and L-arginine with carnosine.

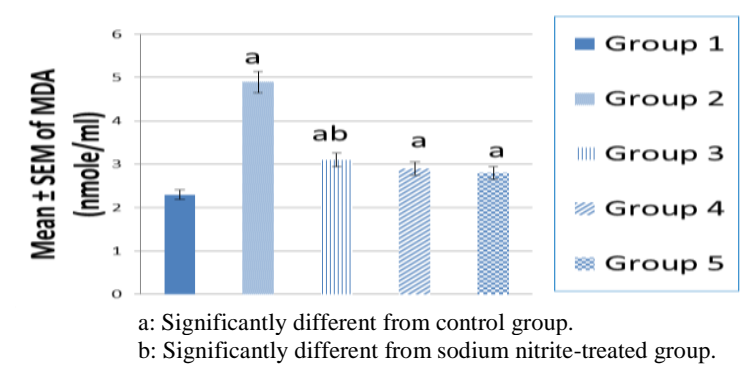

Figure 3 - Serum MDA level of control, hypoxic and pretreated hypoxic rats with L-arginine, or carnosine and L-arginine with carnosine. 
Effects of pretreatment with L-arginine and/or carnosine and their combination on plasma amino acid concentration and different nitrogenous compounds as well as Fischer's ratio.

Table 1 represents plasma amino acids concentration and different nitrogenous compounds in $\mathrm{nmol} / \mathrm{ml}$ as well as Fisher's ratio in the control, hypoxic rats as well as different treated groups. Sodium nitrite treatment caused a highly significant decline in the concentration of proline, citrulline, histidine as well as Fisher's ratio at ( $p<0.001)$, while it caused significant elevation in the concentration of alanine, isoleucine, tyrosine, phenylealanine, tryptophan, urea, ammonia, tuarine and total AAA at $(\mathrm{p}<0.001)$ compared with the control group. The concentration of valine in the hypoxic rats treated with L-arginine was significantly decreased compared with that of the control and hypoxic rats, whilst such treatment caused highly significant decrease in the concentration of leucine and isoleucine compared with the hypoxic group only $(\mathrm{p}<0.001)$.

Table 1 - Plasma amino acid concentration in control, hypoxic rats and different treated groups.

\begin{tabular}{|c|c|c|c|c|c|}
\hline & Group 1 & Group 2 & Group3 & Group4 & Group5 \\
\hline Aspartic acid & $29.3 \pm 9.2$ & $23.6 \pm 2.9$ & $26.9 \pm 6.5$ & $27.9 \pm 4.9$ & $28.2 \pm 6.5$ \\
\hline Hydroxyproline & $60.5 \pm 8.6$ & $54.4 \pm 6.3$ & $56.1 \pm 8.9$ & $55.4 \pm 9.9$ & $53.9 \pm 7.9$ \\
\hline Threonine & $290.3 \pm 28.8$ & $251.2 \pm 23.4^{* * a}$ & $282.3 \pm 14.9^{* \mathrm{~b}}$ & $285.7 \pm 18.1^{* \mathrm{~b}}$ & $218.4 \pm 13.5^{* * * a}$ \\
\hline Serine & $183.4 \pm 9.3$ & $177 \pm 10.2$ & $168.3 \pm 11.9$ & $190 \pm 15.8$ & $188 \pm 20.2$ \\
\hline Asparagine & $48.5 \pm 4.9$ & $38.8 \pm 6.5$ & $38.5 \pm 7.7$ & $47.4 \pm 10.7$ & $40.9 \pm 8.9$ \\
\hline Glutamine & $810.7 \pm 44.3$ & $641.4 \pm 59.6$ & $750.9 \pm 67.7$ & $800.8 \pm 35.2$ & $760.8 \pm 66.9$ \\
\hline roline & $140.0 \pm 6.22$ & $104.9 \pm 14.9^{* * * a}$ & $140.5 \pm 20.2^{* * * \mathrm{~b}}$ & $145.9 \pm 18.8^{* * \mathrm{~b}}$ & $160.6 \pm 15.1^{* * * \mathrm{~b}}$ \\
\hline Alanine & $399.9 \pm 40.2$ & $490.9 \pm 88.9^{* * * a}$ & $430.3 \pm 10.3$ & $439.3 \pm 11.5$ & $470.9 \pm 8.9^{* * a}$ \\
\hline Citrulline & $105.98 \pm 10.3$ & $70.2 \pm 8.1^{* * * *_{a}}$ & $85.2 \pm 8.4^{* * * a}$ & $98.3 \pm 9.1^{* * * \mathrm{~b}}$ & $100 \pm 7.4^{* * * \mathrm{~b}}$ \\
\hline Valine & $199.3 \pm 29.2$ & $227.1 \pm 20.3$ & $130.01 \pm 19.1^{* * * a b}$ & $220.6 \pm 18.9$ & $225.1 \pm 17.6$ \\
\hline Methionine & $58.4 \pm 4.4$ & $68.5 \pm 8.7$ & $47.3 \pm 6.9^{* * * \mathrm{~b}}$ & $81.3 \pm 9.1^{* * * a}$ & $51.5 \pm 8.6^{* * * \mathrm{~b}}$ \\
\hline Isoleucine & $102.9 \pm 10.7$ & $150.5 \pm 8.9^{* * * a}$ & $86.1 \pm 9.3^{* * * b}$ & $130.1 \pm 8.3^{* * * a b}$ & $120.9 \pm 6.6^{* * * a b}$ \\
\hline Leucine & $182.9 \pm 19.9$ & $219.8 \pm 15.5$ & $139.4 \pm 12.9^{* * * \mathrm{~b}}$ & $210 \pm 13.5$ & $175.3 \pm 13.9$ \\
\hline Tyrosine & $60.8 \pm 23.5$ & $148.9 \pm 29.5^{* * * *_{a}}$ & $68.3 \pm 21.7^{* \mathrm{~b}}$ & $107.1 \pm 20.6^{* * * a b}$ & $79.9 \pm 19.9^{* * * \mathrm{~b}}$ \\
\hline Phenylalanine & $73.3 \pm 8.8$ & $160.5 \pm 28.9^{* * * a}$ & $86.2 \pm 20.3^{* * * \mathrm{~b}}$ & $90.3 \pm 21.8^{* * * \mathrm{~b}}$ & $85.7 \pm 23.4^{* * * b}$ \\
\hline Histidine & $72.7 \pm 6.6$ & $42.3 \pm 6.8^{* * * a}$ & $54.4 \pm 5.5^{* * * a}$ & $60.6 \pm 8.3^{* * * b}$ & $56.4 \pm 7.6^{* * * a b}$ \\
\hline Tryptophan & $102.2 \pm 7.7$ & $117.5 \pm 5.1^{* * * a}$ & $68.4 \pm 6.4^{* * * a b}$ & $60.7 \pm 8.1^{* * * a b}$ & $74.6 \pm 9.1^{* * * a b}$ \\
\hline Ornithine & $77.8 \pm 5.5$ & $84.6 \pm 6.9$ & $50.2 \pm 8.4^{* * * a b}$ & $71.4 \pm 6.7^{* * * \mathrm{~b}}$ & $79.1 \pm 4.6^{* * \mathrm{~b}}$ \\
\hline Lysine & $337.7 \pm 45.8$ & $350.5 \pm 66.8$ & $330.8 \pm 44.5$ & $398.4 \pm 39.4$ & $420.5 \pm 39.5^{* * * a}$ \\
\hline Arginine & $310.6 \pm 19.9$ & $279.5 \pm 39.2$ & $300.2 \pm 34.6$ & $320.6 \pm 44.3$ & $330.3 \pm 22.7^{* \mathrm{~b}}$ \\
\hline aaminoadipic acid & $31.2 \pm 4.1$ & $37.4 \pm 2.9^{* * a}$ & $22.5 \pm 4.2^{* * * a b}$ & $19.2 \pm 3.9^{* * * a b}$ & $25.8 \pm 5.1^{* * * \mathrm{~b}}$ \\
\hline Gutamic acid & $126.7 \pm 23.5$ & $90.5 \pm 20.8^{* * a}$ & $99.6 \pm 23.8$ & $108.3 \pm 19.8$ & $120.4 \pm 24.5$ \\
\hline 1-methyl -histidine & $1.7 \pm 0.22$ & $1.4 \pm 0.32$ & $1.9 \pm 0.36$ & $1.5 \pm 0.11$ & $1.6 \pm 0.41$ \\
\hline Urea & $3209 \pm 130.3$ & $7320 \pm 111.9^{* * * a}$ & $7018 \pm 150.5^{* * * a b}$ & $6911 \pm 133.6^{* * * a b}$ & $6659 \pm 122.6^{* * * a b}$ \\
\hline Asparagine & $284 \pm 23.4$ & $277 \pm 43.6$ & $135 \pm 84.3$ & $219 \pm 33.8$ & $252 \pm 55.4$ \\
\hline Ammonia & $181 \pm 16.8$ & $300 \pm 18.3^{* * * a}$ & $262 \pm 20.3^{* * * a}$ & $333 \pm 23.9^{* * * a b}$ & $358 \pm 20.9^{* * * a b}$ \\
\hline Aminobutyric acid & $7.13 \pm 0.96$ & $5.9 \pm 0.33^{* * * a}$ & $9.6 \pm 0.56^{* * * a b}$ & $6.7 \pm 0.66$ & $7.4 \pm 0.26^{* * * b}$ \\
\hline Taurine & $128 \pm 22.4$ & $218 \pm 25.8^{* * * a}$ & $150 \pm 19.4^{* * * b}$ & $162 \pm 26.6^{* * * b}$ & $96 \pm 28.5^{* * * b}$ \\
\hline Hyomocystine & $0.676 \pm 0.029$ & $0.79 \pm 0.09^{* * a}$ & $0.66 \pm 0.08^{* * * b}$ & $0.71 \pm 0.1$ & $0.77 \pm 0.07$ \\
\hline BCAA & $485.1 \pm 48.3$ & $597.4 \pm 39.3$ & $364 \pm 51.3^{* * * \mathrm{~b}}$ & $260 \pm 45.5^{* * * a b}$ & $521.3 \pm 37.6$ \\
\hline AAA & $134.1 \pm 24.1$ & $309.4 \pm 20.6^{* * * a}$ & $145 \pm 33.8^{* * * \mathrm{~b}}$ & $197 \pm 30.6^{* * * a b}$ & $165.6 \pm 22.5^{* * * b}$ \\
\hline Fischer's ratio & $3.62 \pm 0.32$ & $1.9 \pm 0.26^{* * * a}$ & $2.3 \pm 0.44^{* * * a}$ & $2.8 \pm 0.51^{* * * \mathrm{~b}}$ & $3.147 \pm 0.54^{* * * b}$ \\
\hline
\end{tabular}

$* \mathrm{P}<0.05$, slight significant, $* * \mathrm{P}<0.01$ was considered significant, $* * * \mathrm{P}<0.001$ was considered highly significant; Data are expressed as mean \pm SEM; $n=10$. a: Significantly different from control group. b: Significantly different from sodium nitrite-treated group.

The administration of aforementioned antioxidants before sodium nitrite treatment caused highly significant decline in the concentration of aromatic amino acids, hence the treatment with L- arginine alone, or in combination decreased the concentration of tyrosine and phenylalanine compared with the hypoxic rats. The treatment with carnosine alone caused a highly significant decrease in the concentration of tyrosine and phenylalanine compared with hypoxic group. Ammonia and urea levels were highly significantly increased in the hypoxic group 
compared with that of the control. Interestingly, combined treatment of the hypoxic animals with L- arginine and carnosine exerted a synergistic antioxidant effect indicated by the significant decrease in the urea concentration.

The concentration of total BCAA in the hypoxic rats treated with either L-arginine, or carnosine alone decreased compared to the hypoxic group. Also, the concentration of total AAA was significantly decreased in the groups of the hypoxic rats pretreated with the previous antioxidants either alone, or in combination ( $\mathrm{p}<$ 0.001).Administration of the hypoxic rats with carnosine alone, or in combination with $\mathrm{L}$-arginine significantly increased Fisher's ratio compared to the hypoxic groups, while this ratio was significantly decreased in the groups in which hypoxic rats pretreated with L-arginine compared with the control group $(\mathrm{p}<0.001)$.

\section{DISCUSSION}

Hypoxia is caused by the failure of oxygen supply to reach the blood, resulting in low blood oxygen tension in the arterial and venous blood. The rate of diffusion of oxygen from the blood to the tissue is consequently reduced causing the symptom of oxygen lack. The hypoxic cells are particularly susceptible to oxidative stress, a phenomenon commonly known as "oxygen paradox", leading to free radical generation (Goldfarb and Sen 1994). Free radicals are now directly involved in the pathogenesis of various diseases and aging (Akaike 2001).

Sodium nitrite is widely used as an additive in the cured meat products to fix their color, improves flavor, enhance the palatability, inhibit Clostridium botulinum growth and toxin formation (Sindelar and Andrew 2011, 2012). The administration of sodium nitrite in high concentrations for long time induces hemic hypoxia and impaired cerebral energy. The underlying mechanism of this effect is mainly due to increased methemoglobin formation (Ger et al. 1996; Kanti and Syed 2011; Gluhchevaa et al. 2012). Nitrite methemoglobinemia is known to cause free-radical generation, as nitrite can stimulate the oxidation of ferrous ions in oxyhemoglobin to form methemoglobin as well as various ROS radicals generation, which impaire oxidant / antioxidant balance, causing cellular damage (Gladwin et al. 2004; Muller et al. 2007).
Significant decline in hemoglobin concentration after sodium nitrite treatment as observed in the current study was previously reported by Kohn et al. (2002). L-arg and/or carnosine pretreatment significantly upregulated hemoglobin concentration in the hypoxic rats and their combination gave best result regarding blood hemoglobin concentration. These findings were similar to those of Tarumoto et al. (2007), which found that L-arg administration to anemic elderly patients suffering from renal disease resulted in an increase in their hemoglobin levels.

The pronounced anti-ischemic effects of carnosine in the brain and heart are due to the combination of antioxidant and membrane-protecting activity, proton buffering capacity, formation of complexes with transition metals, and regulation of macrophage function (Stvolinsky and Dobrota 2000). ROS not only cause the peroxidation of the polyunsaturated fatty acids in the neuronal membrane structure, but also affect the proteins localized within the membrane, therefore altering the three dimensional structure of the membrane, and finally disrupting its selective permeability characteristics (Kanti and Syed 2011). This leads to the consequent release of injury marker enzymes whose release is correlated with the changes in plasma membrane integrity and/or permeability. These were in harmony with the results of the present work in which hypoxic rats showed a slight significant increase in the serum LDH activity. Such increase offers another supporting evidence of hypoxic oxidative damage due to sodium nitrite treatment. However, the levels of these markers were significantly reduced in L-arg and/or carnosine pretreated hypoxic rats. It has been previously documented that ATP level is markedly reduced in the hypoxic brain tissue and that idebenone and/or L-arg pretreatment ameliorates the depleting effect of nitrite-induced hypoxia on brain ATP content, suggesting that their protective effect may be mediated through improving the cerebral energy metabolism (Nayira et al. 2010). L-arg itself has been reported to protect the tissues and organs against ischemiareperfusion injury as evidenced from the significant increase in the level of total antioxidants, and the decrease in the level of MDA in the rats (Krauss et al. 2009).

The antioxidative action of carnosine are not only due to the binding of lipid oxidation products, but also due to the interaction with active oxygen species. Carnosine may also serve as a scavenger 
of peroxyl and hydroxyl radicals and singlet oxygen and superoxide anion oxygen, and neutralize hypochlorite anions by forming stable chloramine complexes (Severina et al. 2000). The antioxidative properties of carnosine make it an effective treatment in a variety of inflammatory conditions, related to cellular membrane damage (Zaloga et al. 1997).

Zhang et al. (2011) reported that the pretreatment with carnosine significantly reduced the infarct volume and decreased MDA level in the hypoxiaischemia brain damage rats. The results of the present work were similar to these findings. Pretreatment with L-arg and/or carnosine, either alone, or in combination significantly down regulated the MDA serum level.

Almost all the oxygen captured by the lungs during the critical illness is utilized for ATP synthesis by the oxidizing glucose and fatty acids in the mitochondria of the cells. As a consequence, inadequate ATP is produced by the hypoxic cells, leading to cellular metabolic dysfunction (Seon et al. 2013).

BCAAs represent much of the mass of muscle for the production of ATP and protein synthesis after incorporation into the tissue (Elwyn 1970). Oxygen deficiency prevents the use of BCAAs, as the mitochondrial electron transfer system is unable to operate smoothly. For this reason, the concentration of BCAAs in the plasma increases as a consequence of oxygen deficiency. On the other hand, tyrosine and phenylalanine are mainly metabolized by the liver. Thus, an increase in the levels of AAAs results from the attenuation of the metabolic capacity of the liver caused by the exposure to hypoxic conditions (Haruhiro and Akiko 2011). Zunić et al. (1993) reported increased total free amino acid and urea concentrations in the plasma, indicating protein and amino acid metabolic alterations in anemic Belgrade laboratory (b/b) rats. Plasma alanine, glutamine, tyrosine, and phenylalanine concentrations were increased. The significantly reduced molar ratio between valine + leucine + isoleucine and phenylalanine + tyrosine suggested severe disturbance in the hepatic energy-producing system and derangement of hepatic energy status. A better oxygen supply to the liver could normalize the hepatic energy status. These findings suggested that the metabolic disturbances in the $\mathrm{b} / \mathrm{b}$ rat were the consequence of hypoxia due to the severe anemia (Zunić et al. 1993).
In the current study, plasma amino acids pattern was estimated in the hemic hypoxic group. The levels of the BCAAs as well as AAAs were elevated in the hypoxic group, whereas a lower Fischer's ratio was observed. In L-arg and/or carnosine pretreated hypoxic rats, BCAAs and AAAs levels were significantly decreased, whereas Fischer's ratio was increased compared with the hypoxic group. These results were in accordance with that of Haruhiro and Akiko (2011).

In the present study, plasma arginine and citrulline levels declined in the hypoxic rats, showing the alteration in the function of the hepatic urea cycle, which depended mainly on the ATP, which was depleted after sodium nitrite administration. The levels of these amino acids were increased in Larg and carnosine, either alone, or in combination pretreatment compared with the hypoxic group. Similar results have been documented by Zunić et al. (1993) and Haruhiro and Akiko (2011).

Plasma proline level was decreased in the hypoxic rats. This resulted in ATP depletion, which led to the inhibition of $\gamma$-glutamyl kinase, This, in turn, affected the synthesis of proline. Administration of aforementioned antioxidants up regulated proline level compared with the hypoxic group. The reduction in the citrulline and proline levels is typical of acute hypoxic hypoxia (Haruhiro and Akiko 2011).

It has been reported that chronic hypoxia decreases the cellular content of glutamate, but increases that of glutamine. Taken together, the hypoxia-induced changes in the enzymes related to glutamate metabolism and transport are consistent with a decrease in the extracellular concentration of glutamate (Kobayashi and Milhorn 2001). Other findings suggested partial protection for the female rats against early hypoxic insult in the cerebellum, and that down-regulation of $\alpha$-aminobutyric (GABA) - A receptors (Eung-Kwon et al. 2011). Similar results were obtained in the present study; the level of glutamate and GABA was decreased, whereas use of the antioxidants modulated these amino acids alterations.

Wijekoon et al. (2004) reported that plasma concentrations of the gluconeogenic amino acids aspartate, serine, glutamine, glycine, and histidine were decreased, whereas taurine, alphaaminoadipic acid, methionine, phenylalanine, tryptophan, and the three branched-chain amino acids levels were significantly increased in the Zucker diabetic fatty (ZDF Gmi fa/fa) rat during 
insulin-resistant stage . Also, it was reported that hypoxia caused a considerable increase in plasma taurine and phosphoserine levels, while the remaining amino acids (except valine, cystine, isoleucine, leucine and anserine) were decreased significantly (al-Bekairi 1989). These were similar to the present results, as the pretreatment with Larg and carnosine, either alone, or in combination nearly normalized the previously mentioned amino acids levels compared with that of hypoxic group.

\section{CONCLUSION}

Fischer's ratio was useful tool for evaluating the level of acute hypoxia without systemic tissue damage and to evaluate the synergy between L-arg and carnosine in ameliorating the amino acids pattern alteration induced by sodium nitrite.

\section{ACKNOWLEDGMENT}

This research project was supported by a grant from the 'Research Center for Female Scientific and Medical Colleges', Deanship of Scientific Research, King Saud University.

\section{REFERENCES}

Akaike T. Role of free radicals in viral pathogenesis and mutation. Rev Med Virol. 2001; 11 (2): 87-101.

Al-Bekairi AM. Effect of hypoxia and/or cold stress on plasma and brain amino acids in rat. Res Commun Chem Pathol Pharmacol. 1989; 64 (2): 287-297.

Ali SA. Evaluation of immunological effect of beta alanyl-1-histidine against Schistosoma mansoni antigens of Rabbits. J Infect Dev Ctries. 2012; 6: 166-175.

Amerisco SF, Sahai S. Mechanisms of ischemia in situ vascular occlusive disease. 1997 In Welch KMA, Caplan LR, Reis DJ, Siesjö BK (Eds.) Primer on Cerebrovascular Disease. Academic Press, San Diego. pp. 9-285.

Andrew PJ, Mayer B. Enzymatic function of nitric oxide synthases. Cardiovasc Res. 1999; 43 (3): 521 531.

Bath PMW, Hassall DG, Gladwin A-M, Palmer RMJ, Martin JF. Nitric oxide and prostacyclin: divergence of inhibitory effects on monocyte chemotaxis and adhesion to endothelium in vitro. Arterioscler Thromb. 1991; 11: 254-260.
Cernadas MR, López-Farré A, Riesco A, Gallego MJ, Espinosa G, Digiuni E, et al. Renal and systemic effects of aminoacids administered separately: comparison between L-arginine and non-nitric oxide donor aminoacids. J Pharmacol Exp Ther. 1992; 263: 1023-1029.

Drabkin DL and Austin HJ. Spectrophotometric studies: II. Preparations from washed blood cells: nitric oxide hemoglobin and sulfhemoglobin. $J$ Biol Chem. 1935; 112: 51-65

El-Missiry MA, Othman AI, Amer MA. L-Arg ameliorates oxidative stress in alloxan-induced experimental diabetes mellitus. J Appl Toxicol. 2004; 24 (2): 93-97.

Elwyn DH. The role of the liver in regulation of amino acid and protein metabolism. 1970 In: Munro HN, editor. New York: Academic Press. Mammalian Protein Metabolism. pp. 523-557.

Endres M, Biniszkiewicz D, Sobol RW, Harás Ch, Ahmadi M, Katchanovb J, et al. Increased postischemic brain injury in mice deficient in uracilDNA glycosylase. J Clin Invest. 2004; 113: 17111721.

Eung-Kwon P, Audrey JY, Bhoomika A, Gary WL, Daniel DN, Yong K, et al. Perinatal intermittent hypoxia alters $\gamma$-aminobutyric acid: a receptor levels in rat cerebellum. Int J Dev Neurosci. 2011; 29 (8): 819-826.

Ferber JL, Chien KR, Mittnacht S. The pathogenesis of irreversible cell injury in ischemia. Am J Pathol. 1981; 102: 271-281.

Fischer JE, Rosen HM, Ebeid AM, James JH, Keane JM, Soeters PB. The effect of normalization of plasma amino acids on hepatic encephalopathy in man. Surgery. 1976; 80: 77-91.

Flock EV, Mann FC, Bollman JL. Free amino acids in plasma and muscle following total removal of the liver. J Biol Chem. 1951; 192: 293-300.

Ger J, Kao H, Shih TS, Deng JF. Fatal toxic methemoglobinemia due to occupational exposure to methyl nitrite. Clin Med J. 1996, 57: S78.

Gladwin MT, Crawford JH, Patel RP. The biochemistry of nitric oxide, nitrite, and hemoglobin: role in blood flow regulation. Free Rad Biol Med. 2004; 36: 707717.

Gluhchevaa Y, Ivanovb I, Petrovaa E, Pavlovaa E, Vladova I. Sodium nitrite-induced hematological and hemorheological changes in rats. Series On Biomechanics. 2012; 27 (3-4): 53-58.

Gokce N. L-Arginine and hypertension. J Nutr. 2004; 134 (10 Suppl): 2807-2811.

Goldfarb AH, Sen CK. Antioxidant supplementation and control of oxygen. 1994 In: Sen CK, Packer L, Osmo H. (Eds.). Exercise And Oxygen Toxicity. pp. 163-190. 
Gonchar O, Mankovskaya I, Klyuchko E. Role of complex nucleosides in the reversal of oxidative stress and metabolic disorders induced by acute nitrite poisoning. I J P. 2006; 38: 414-418.

Hall ED, Andrus PK, Smith SL, Oostveen JA, Scherch HM, Lutzke BS; et al. Neuroprotective efficacy of microvascularly-localized versus brain-penetrating antioxidants. Acta Neurochir. 1996; 66: 107-113.

Halliwell B. Reactive oxygen species and the central nervous system. J Neurochem. 1992; 59: 1609-1623.

Haruhiro M, Akiko Y. Profile of Plasma Amino Acid Levels in Rats Exposed to Acute Hypoxic Hypoxia. Indian J Clin Biochem. 2011; 26 (4): 416-419.

Hishikawa K, Nakaki T, Tsuda M, Esumi H, Ohshima $\mathrm{H}$, Suzuki H, et al. Effect of systemic L-arginine administration on hemodynamic and nitric oxide release in man. Jpn Heart J. 1992; 33: 41-48.

Huang Z, Huang PL, Ma J, Meng W, Ayata C, Fishman MC, et al. Enlarged infarcts in endothelial nitric oxide synthase knockout mice are attenuated by nitro-L-arginine. J Cereb Blood Flow Meta. 1996; 16: 981.

Kanti BP, Syed I R. Biomarkers of oxidative stress in red blood cells. Biomed Pap Med Fac Univ Palacky Olomouc Czech Repub. 2011; 155.

Kedenburg CP. A lithium buffer system for accelerated single-column amino acid analysis in physiological fluids. Anal Biochem. 1971; 40: 35-42.

Kobayashi S, Millhorn DE. Hypoxia regulates glutamate metabolism and membrane transport in rat PC12 cells. J Neurochem. 2001; 76 (6):1935-1948.

Kohn MC, Melnick RL, Ye F, Portier CJ. Pharmacokinetics of sodium nitrite induced methemoglobinemia in the rat. Drug Metab Dispos. 2002; 30: 676-683.

Krauss H, Jablecka A, Sosnowski P, Bogdanski P. Influence of 1-arginine 255525 on the nitric oxide concentration and level of oxidative stress during ischemia-reperfusion injury in a rat model. Int J Clin Pharmacol Ther. 2009; 47 (8): 533-538.

Linberg R, Conover CD, Shum KL, Shorr RG. "Hemoglobin based oxygen carriers: how much methemoglobin is too much?". Artif Cells Blood Substit Immobil Biotechnol. 1998; 26 (2):133-148.

Mehta S, Stewart DJ, Levy RD. The hypotensive effect of L-arginine is associated with increased expired nitric oxide in humans. Chest. 1996; 109: 1550-1555.

Mohr JP, Caplan LR, Melski JW. The Harvard cooperative stroke registry: a prospective registry. Neurology. 1978; 28: 754-762.

Muller FL, Lustgarten MS, Jang Y, Richardson A, Van Remmen H. Trends in oxidative aging theories. Free Radic Biol Med. 2007; 43 (4): 477-503.

Muratsubaki H, Enomoto K, Ichijoh Y, Yamamoto Y. Hypertriglyceridemia associated with decreased postheparin plasma hepatic triglyceride lipase activity in hypoxic rats. Arch Physiol Biochem. 2003; 111: 449454.
Nayira AA, Zeenat FZ, Amal JF, Mohamed MS, Hazar Y. Nitric oxide pros and cons: The role of 1-arginine, a nitric oxide precursor, and idebenone, a coenzyme$\mathrm{Q}$ analogue in ameliorating cerebral hypoxia in rat. Brain Research Bulletin. 2010; 83: 49-56.

Ohkawa H, Ohishi N, Yagi K. Assay for lipid peroxidation in animal tissues by thiobarbituric acid reaction. Annals of Biochemistry. 1979; 95: 351-358.

Palozza P, Lubertoc S, Calviellog S, Ricc P, Bartoli GM. Antioxidant and prooxidant role of â-carotene in murine normal and tumor thymocytes: effects of oxygen partial pressure. Free Radic Biol Med. 1997; 22: 1065-1073.

Pluta RM, Rak R, Wink DA, Woodward JJ, Khaldi A, OldWeld EH, et al. Effects of nitric oxide on reactive oxygen species production and infarction size after brain reperfusion injury. Neurosurgery. 2001; 48: 884-892.

Salter M, Duffy C, Garthwaite J, Strijbos PJLM. Ex vivo measurement of brain tissue nitrite and nitrate accurately reflects nitric oxide synthase activity in vivo. J Neurochem. 1996; 66: 1683-1690.

Schutz E, Wiland E, Hensel A, Niedmann P, Dreiss A, Armstrong VW, et al. Suppression of leukocyteenhanced cold ischemia reperfusion injury of liver endothelium with the benzoquinone antioxidant idebenone. Clin Biochem. 1997; 30: 619-624.

Senberg JS, Ridnour LA, Espey MG, Wink DA, Roberts DD. Nitric oxide in wound-healing. Microsurgery. 2005; 25 (5): 442-451.

Seon-Jin L, Jinglan Z, Augustine MKC, Hong PK. Mitochondrial Dysfunction Induces Formation of Lipid Droplets as a Generalized Response to Stress. Oxid Med Cell Longev. 2013:1-10.

Severina IS, Bussygina OG, Pyatakova NV. Carnosine as a Regulator of Soluble Guanylate Cyclase. Biochemistry. 2000; 65 (7): 783-788.

Sims R, Anderson MF. Mitochondrial contributions to tissue damage in stroke. Neurochem Int. 2002; 40; 511-526.

Sindelar J, Andrew M. Sodium Nitrite in Processed Meat and Poultry Meats: A Review of Curing and Examining the Risk/Benefit of Its Use. American Meat Science Association. 2011; 3: 1-14.

Sindelar J, Andrew M. Human safety controversies surrounding nitrate and nitrite in the diet. Nitric Oxide. 2012; 26 (4): 259-266.

Stechmiller JK, Childress B, Cowan L. Arginine supplementation and wound healing. Nutr Clin Pract. 2005; 20: 52-61.

Stvolinsky SL, Dobrota D. Anti-ischemic activity of carnosine. Biochemistry (Mosc). 2000; 65 (7): 849855.

Tarumoto T, Imagawa S, Kobayashi M, Hirayama A, Ozawa K, Nagasawa T. 1-Arginine administration reverses anemia associated with renal disease. Int $J$ Hematol. 2007; 86: 126-129. 
Wijekoon EP, Skinner C, Brosnan ME, Brosnan JT. Amino acid metabolism in the Zucker diabetic fatty rat: effects of insulin resistance and of type 2 diabetes. Can J Physiol Pharmacol. 2004; 82 (7): 506-514.

Wink DA, Cook JA, Pacelli R, Liebmann J, Krishna MC, Mitchell JB. Nitric oxide (NO) protects against cellular damage by reactive oxygen species. Toxicol Lett. 1995; 82-83: 221-226.

Witte MB, Barbul A. Arginine physiology and its implication for wound healing. Wound Repair Regen. 2003; 11 (6): 419-423.

Wu G, Jaeger LA, Bazer FW, Rhoads JM. Arginine deficiency in preterm infants: biochemical mechanisms and nutritional implications. $J$ Nutr Biochem. 2004; 15 (8): 442-451.

Zaloga GP, Roberts PR, Black KW, Lin M, ZapataSudo G, Sudo RT, et al. Carnosine is a novel peptide modulator of intracellular calcium and contractility in cardiac cells. Am J Physiol. 1997; 72(1): 462-468.

Zhang F, Iadecola C. Reduction of focal cerebral ischemic damage by delayed treatment with nitric oxide donors. J Cereb Blood Flow Metab. 1994; 14: 574-580.
Zhang X, Song L, Cheng X, Yang Y, Luan B, Jia L, et al. Carnosine pretreatment protects against hypoxiaischemia brain damage in the neonatal rat model. Eur J Pharmacol. 2011; 667 (1-3): 202-207.

Zunić G, Rolović Z, Basara N, Simović M, Vasiljevski M. Decreased plasma proteins, increased total plasma-free amino acids, and disturbed amino acid metabolism in the hereditary severe anemia of the Belgrade laboratory (b/b) rat. Proc Soc Exp Biol Med. 1993; 203 (3): 366-371.
Received: April 22, 2015; Accepted: June 172015. 